\title{
Temporal allocation of metabolic tolerance to transgenic Bt cotton in beet armyworm, Spodoptera exigua (Hübner)
}

\author{
GUO JianYing $^{1 *}$, WU Gang $^{1,2} \&$ WAN FangHao ${ }^{1 *}$ \\ ${ }^{1}$ State Key Laboratory for Biology of Plant Diseases and Insect Pests, Institute of Plant Protection, \\ Chinese Academy of Agricultural Sciences, Beijing 100193, China; \\ ${ }^{2}$ College of Plant Sciences and Technology, Huazhong Agricultural University, Hubei 430070, China
}

Received July 2, 2009; accepted July 31, 2009

\begin{abstract}
Digestive and detoxification enzyme activity and nutrient composition were examined in the body of fourth instar beet armyworms, Spodoptera exigua (Hübner), fed on transgenic Bacillus thuringiensis (Bt) and non-Bt cotton for different time periods. Nutrient composition and specific enzyme activities differed significantly between the S. exigua fed Bt vs. non-Bt cotton. At 1 , 6 and $24 \mathrm{~h}$, free fatty acid and glucose levels were significantly lower in S. exigua fed on Bt cotton than those fed on non-Bt cotton. S. exigua fed on Bt cotton had significantly higher trypsin and total superoxide dismutase (T-SOD) activities and significantly lower lipase, carboxylesterase and acetylcholinesterase activities than non-Bt fed worms for all feeding time periods. Differences were also observed among feeding times within each cotton variety group. Significantly lower free fatty acid and total amino acid were observed in S. exigua fed on Bt cotton for $24 \mathrm{~h}$ than in those fed for $1 \mathrm{~h}$. Significantly lower activities of lipase and trypsin were detected in S. exigua fed on Bt cotton for $24 \mathrm{~h}$ than those for 1 and $4 \mathrm{~h}$. However, carboxylesterase and acetylcholinesterase activities in $S$. exigua fed on Bt cotton for $24 \mathrm{~h}$ were significantly higher than those for 1,4 and $6 \mathrm{~h}$. The interaction between cotton variety and feeding time significantly affected the activities of lipase, trypsin, acetylcholinesterase and T-SOD enzymes in S. exigua. Measuring the temporal allocation of protection and detoxification enzyme activities in the body of $S$. exigua in response to $B$. thuringiensis can provide a meaningful evaluation on the metabolic tolerance of herbivorous insects under the continuous selection pressure of a toxic protein.
\end{abstract}

Bacillus thuringiensis, Spodoptera exigua, detoxification enzyme, carboxylesterase, acetylcholinesterase

Citation: Guo J Y, Wu G, Wan F H. Temporal allocation of metabolic tolerance to transgenic Bt cotton in beet armyworm, Spodoptera exigua (Hübner). Sci China Life Sci, 2011, 54: 152-158, doi: 10.1007/s11427-010-4133-y

Crop losses caused by insect pests, estimated at $10 \%-20 \%$ for major crops, are a significant factor limiting food production [1]. Insecticide application against the larval stage of herbivorous insects is the primary control method; however, a high tolerance to most insecticides and associated environmental problems may jeopardize their continued use [2]. Genetically engineered cotton plants, which exhibit enhanced-resistance or tolerance to insect pests, are a major success of transgenic technology. During the past decade, Bacillus thuringiensis (Bt) cotton (Gossypium hirsutum)

*Corresponding author (email: guojy@ mail.caas.net.cn; wanfh@ mail.caas.net.cn) plantings in China have expanded quickly and transgenic Bt cotton is currently the main genetically modified (GM) crop commercialized on a large scale in this country $[3,4]$.

Bt plants have great potential in integrated pest management (IPM) programs. They may be used to complement the effects of other biological control agents because of their higher selectivity than most insecticides [4-6]. It has been concluded that the mechanism of action of the Bt Cry proteins involves solubilization of the crystal in the insect midgut, proteolytic processing of the protoxin by midgut proteases, binding of the Cry toxin to midgut receptors, and insertion of the toxin into the apical membrane to create ion 
channels or pores [7]. When ingested by larvae, toxin proteins bind to specific receptors in the midgut region, and toxin binding in susceptible insects disrupts the midgut epithelium, thereby causing overall toxic effects and ultimately resulting in larval death [8]. Transgenic Bt cotton that expresses the Cry1Ac toxin is highly effective against the major lepidopterous cotton insect pests [9]. Multiple field trials have proven that $\mathrm{Bt}$ cotton exhibits high insecticidal efficacy against larvae of tobacco budworm, cotton bollworm and other target lepidopterous pests and decreases the population densities of these target pest species in cotton fields [10-12]. However, the evolution of resistance or tolerance to $\mathrm{Bt}$ toxins by herbivorous insects is a serious threat to the efficacy of Bt-based insecticides and toxin-producing transgenic plants, which are generally pest specific and environmentally safe $[13,14]$.

Not all lepidopteran pest species are equally susceptible to $B$. thuringiensis. Some lepidopteran species can survive after feeding on transgenic Bt cotton expressing Cry1Ac toxin $[15,16]$. Some non-lepidopteran herbivores are also unaffected by the toxin. Beet armyworm, Spodoptera exigua (Hübner), is an important pest in numerous crops, including cotton, and causes economic damage in China. However, S. exigua is not a target pest of currently commercialized transgenic $\mathrm{Bt}$ cotton varieties in China. It was added to the prediction list of outbreaking insect pests in China in 2001 [17]. The failure of chemical measures to control this insect has shifted the emphasis towards other effective strategies (e.g., transgenic crops or natural enemies) in an IPM program. However, the effect of $\mathrm{Bt}$ transgenic plants on non-target organisms is becoming increasingly important in agro-ecosystems [5]. There is concern about the widespread development of Bt resistance or tolerance in beet armyworm due to reports of field resistance to Bt toxins in several lepidopteran families [13]. Guo et al. [18] reported that significantly lower carboxylesterase (CarE) was observed in the larvae of Micromelalopha troglodyte fed on the leaves of transgenic poplars and revealed that these plants disturbed the insect metabolism mainly by restraining the activities of CarE in the midgut of larvae and subsequently caused larval death. Because the control efficacy of Bt cotton depends on the expression of Cry genes through synthesis of insecticidal protein [19], the temporal variation of efficacy may lead to insufficient control of herbivorous insects and the evolution of resistance or tolerance [20]. To date, there is limited information regarding the temporal variation of enzymes activities in the body of $S$. exigua in response to $B$. thuringiensis and further evaluation of these factors is necessary.

In this study, nutrient composition (protein, total amino acid, free fatty acid and glucose) and activities of digestive enzymes (i.e., lipase, trypsin and amylase) and protection and detoxification enzymes (i.e., CarE, acetylcholinesterase (AChE) and total superoxide dismutase (T-SOD)) were examined in $S$. exigua fed on transgenic Bt cotton (cv.
GK-12) or non-Bt cotton (cv. Simian-3) for different time periods. This study aimed to (i) quantify the temporal allocation of metabolic tolerance in the body of $S$. exigua in response to $B$. thuringiensis; (ii) evaluate the interaction between cotton variety (GK-12 vs. Simian-3) and beet armyworm feeding time (i.e., 1, 4, 6 and $24 \mathrm{~h}$ ) on digestive and detoxification enzymes and nutrient composition in $S$. exigua.

\section{Materials and methods}

\subsection{Cotton variety and growth conditions}

Two cotton cultivars were used in the study, including a transgenic Bt cultivar 'GK-12' and its parental non-transgenic cultivar 'Simian-3'. Both cultivars were planted in plastic pots $(15 \mathrm{~cm}$ in diameter, $13 \mathrm{~cm}$ in height, one plant per pot) in a thermostatic chamber, in which the temperature was maintained at $(28 \pm 1)^{\circ} \mathrm{C}$ and relative humidity $(\mathrm{RH})$ was maintained at $70 \%-80 \%$. Eighty pots for each cotton cultivar were randomly placed in the thermostatic chamber and re-randomized once a week to minimize position effects. No chemical fertilizers or insecticides were used throughout the entire experiment.

\subsection{Beet armyworm stocks}

Egg masses of $S$. exigua were obtained from the Insect Virology Laboratory, Institute of Zoology, Chinese Academy of Sciences (CAS), and hatched in a growth chamber (PRX500D-30; Haishu Safe Apparatus, Ningbo, Zhejiang Province, China). The chamber was maintained at $75 \% \pm 5 \% \mathrm{RH}$, $(28 \pm 0.5)^{\circ} \mathrm{C}$, with a photoperiod of 14 -h light/10-h dark at $30000 \mathrm{LX}$ of active radiation supplied by $26 \mathrm{~W}$ fluorescent lamps $(n=39)$. The newly hatched larvae were fed on artificial diet as described by Li et al. [21].

\subsection{Beet armyworm feeding treatments}

The beet armyworm feeding experiment was carried out in another thermostatic chamber, using the same conditions as mentioned above for the cotton growth.

During the seven-leaf stage (approximately 35-40 d after planting) of cotton plants, the fourth instar S. exigua larvae from laboratory cultures were randomly collected from the growth chamber as described above. Larvae were placed on the fourth leaf from the base of the plant, with one larva per pot. Each set was placed in a cubic cage $(60 \mathrm{~cm}$ for each side) covered with a fine mesh net to prevent the incursion of other insects. Five pots were used with four replications per cotton cultivar for four treatments of S. exigua (i.e., feeding time for 1, 4, 6 and $24 \mathrm{~h}$ ), with a total of 20 insects per feeding time. After $S$. exigua inoculation for 1, 4, 6 and $24 \mathrm{~h}$, beet armyworm larvae were collected to measure di- 
gestive and detoxification enzyme activities and nutrient compositions.

\subsection{Beet armyworm enzyme activity assays}

Biochemical assays were conducted to test for significant changes in enzyme activities in $S$. exigua in response to $B$. thuringiensis. Four nutrient composition types (protein, total amino acid, free fatty acid and glucose), three digestive enzymes (lipase, trypsin, amylase) and three protection and detoxification enzymes (CarE, AChE, T-SOD) were used to test for metabolic changes in S. exigua larvae fed on transgenic Bt cotton (cv. GK-12) or non-Bt cotton (cv. Simian-3). CarE activity was determined by the method of Van Asperen [22]. Nutrient compositions and other enzymes activities were measured according to the manufacturer's instructions for assay kits (Nanjing Jiancheng Co., Ltd., Nanjing, Jiangsu Province, China). Enzyme activities were presented relative to protein concentration, which was determined using the method of Bradford [23] with bovine serum albumin (Nanjing Jiancheng Co., Ltd., Nanjing, Jiangsu Province, China) as the standard.

\subsection{Data analysis}

One-way analysis of variance (ANOVA) [24] was used to compare differences in nutrient composition and enzyme activity in $S$. exigua after being fed on transgenic Bt cotton (cv. GK-12) and non-Bt cotton (cv. Simian-3) for different time periods. Two-way ANOVAs were used to analyze the impacts of cotton cultivar and beet armyworm feeding time, along with their interactions, on the above indices. Differences between means were compared using the least significant difference (LSD) test.

\section{Results}

\subsection{Nutrient compositions in the fourth instar $S$. exigua larvae fed on transgenic Bt cotton vs. non-Bt cotton}

\subsubsection{Protein and total amino acid}

Cotton variety significantly affected the protein $(P<0.001)$ and total amino acid $(P<0.01)$ levels in the body of $S$. exigua. Interactions between cotton variety and $S$. exigua feeding time significantly influenced protein $(P<0.05)$ and total amino acid $(P<0.01)$ levels (Table 1$)$.

Protein level in $S$. exigua increased significantly after being fed on Bt cotton for $6(P<0.01)$ and $24 \mathrm{~h}(P<0.001)$, compared with those fed on non-Bt cotton for the same time periods. Significantly lower protein levels were detected in S. exigua fed on Bt cotton for $1 \mathrm{~h}$ than those for 4,6 and 24 h $(F=3.74, \mathrm{~d} f=3,12, P=0.0415)$ (Figure 1A). Total amino acids in $S$. exigua also decreased significantly after being fed on Bt cotton for $6(P<0.01)$ and $24 \mathrm{~h}(P<0.001)$, compared
Table 1 Effects of cotton variety, beet armyworm feeding time and their interactions on nutrient compositions and the activities of digestive enzymes and detoxification enzymes in fourth instar Spodoptera exigua larvae $^{\text {a) }}$

\begin{tabular}{cccc}
\hline Measured indexes & Variety & Time & Variety $\times$ time \\
\hline Protein & $0.0001^{* * *}$ & 0.4961 & $0.0218^{* *}$ \\
Total amino acid & $0.0072^{* *}$ & 0.066 & $0.0026^{* *}$ \\
Free fatty acid & $0.0001^{* * *}$ & $0.0344^{*}$ & 0.1657 \\
Glucose & $0.0001^{* * *}$ & 0.9551 & 0.3166 \\
Lipase & $0.0001^{* * *}$ & 0.9595 & $0.0019^{* *}$ \\
Trypsin & $0.0001^{* * *}$ & $0.0001^{* * *}$ & $0.0001^{* * *}$ \\
Amylase & $0.5619^{* * *}$ & 0.9711 & 0.8659 \\
CarE & $0.0001^{* * *}$ & $0.0036^{* *}$ & 0.1061 \\
AChE & $0.0001^{* * *}$ & 0.7183 & $0.0018^{* *}$ \\
T-SOD & $0.0001^{* * *}$ & 0.0925 & $0.0004^{* * *}$ \\
\hline
\end{tabular}

a) Variety, cotton variety, Simian-3 and GK-12; time, beet armyworm feeding time for 1, 4, 6 and $24 \mathrm{~h}$; CarE, carboxylesterase; AChE, acetylcholinesterase; T-SOD, total superoxide dismutase. *, $P<0.05$; **, $P<0.01$; $* * *, P<0.001$.

with those fed on non-Bt cotton for the same period. Significantly higher total amino acids were detected in $S$. exigua fed on Bt cotton for 1 and $4 \mathrm{~h}$ than those fed for 6 and $24 \mathrm{~h}(F=15.84, \mathrm{~d} f=3,12, P=0.0002)$ (Figure 1B).

\subsubsection{Free fatty acid and glucose}

Cotton variety significantly affected free fatty acid $(P<$ $0.001)$ and glucose $(P<0.001)$ levels in $S$. exigua. Beet armyworm feeding time also significantly influenced the level of free fatty acid $(P<0.05)$ (Table 1$)$.

The free fatty acid level in $S$. exigua decreased significantly after being fed on Bt cotton for $6(P<0.001)$ and $24 \mathrm{~h}$ $(P<0.001)$, compared with those fed on non-Bt cotton for the same period (Figure 1C). Significantly lower glucose $(P<0.01)$ was detected in $S$. exigua fed on Bt cotton for 1,6 and $24 \mathrm{~h}$, compared with those fed on non-Bt cotton for the same period (Figure 1D).

\subsection{Activities of the digestive enzymes in fourth instar $S$. exigua larvae fed on transgenic Bt cotton vs. non-Bt} cotton

\subsubsection{Lipase}

Cotton variety significantly affected $S$. exigua lipase activity $(P<0.001)$. Interactions between cotton variety and feeding time significantly influenced the lipase activity in $S$. exigua $(P<0.01)$ (Table 1).

Lipase activity in $S$. exigua decreased significantly after being fed on Bt cotton for $24 \mathrm{~h}(F=6.13, \mathrm{~d} f=3,12, P=0.009)$ than those for 1, 4 and $6 \mathrm{~h}$. Significantly lower lipase activity was detected in $S$. exigua fed on $\mathrm{Bt}$ cotton for 1 $(P<0.001), 4(P<0.01), 6(P<0.001)$ and $24 \mathrm{~h}(P<0.001)$, compared with those on non-Bt cotton for the same periods (Figure 2A). 

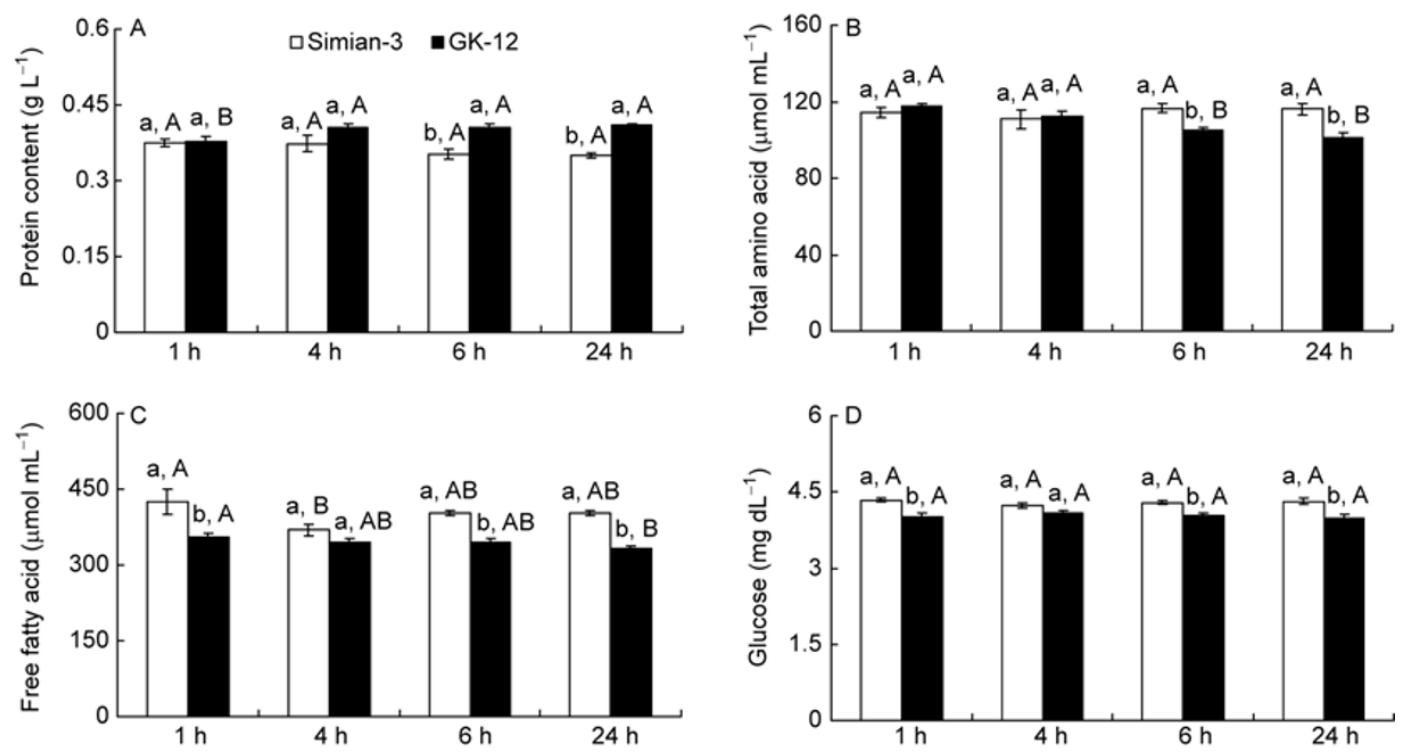

Figure 1 Mean \pm SE nutrient compositions in the body of fourth instar Spodoptera exigua larvae fed on transgenic Bt cotton (cv. GK-12) or non-Bt cotton (cv. Simian-3) for different times (1, 4,6 and $24 \mathrm{~h}$ ). Data within the same group that are indicated with different lowercase letters are significantly different $(P<0.05)$ between different cotton varieties; data within the same group that are indicated with different uppercase letters are significantly different $(P<0.05)$ among different feeding times. A, protein; B, total amino acid; C, free fatty acid; D, glucose.
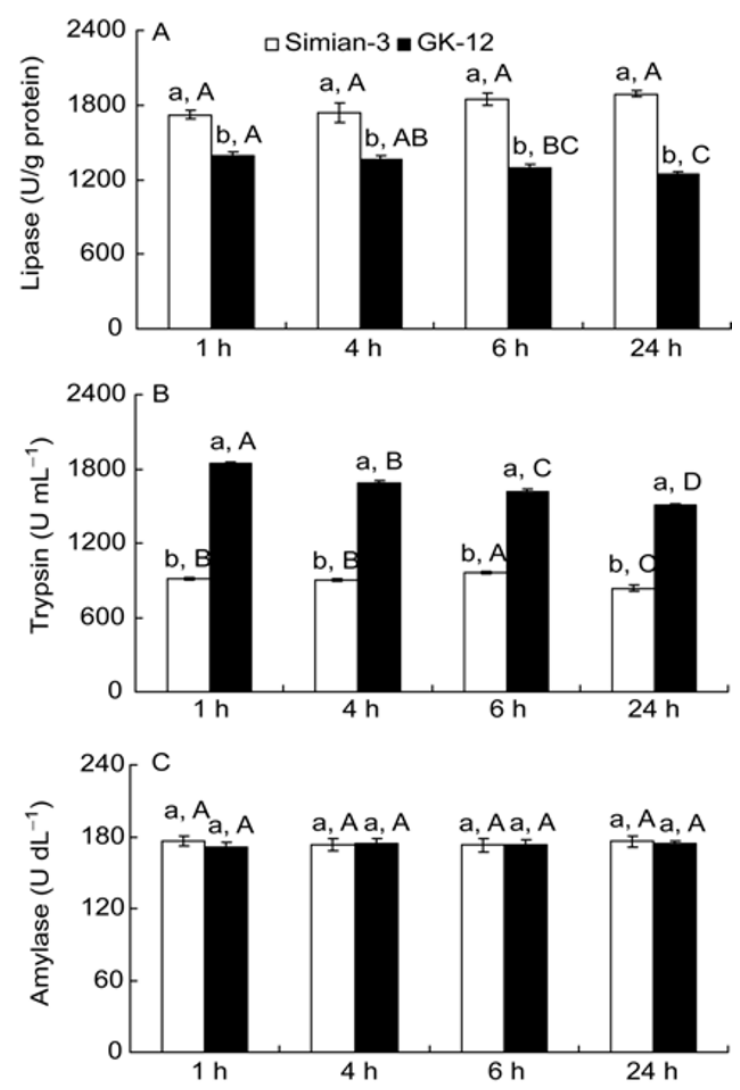

Figure 2 Mean \pm SE digestive enzyme activities in the body of fourth instar Spodoptera exigua larvae fed on Bt cotton (cv. GK-12) or non-Bt cotton (cv. Simian-3) for different times (1, 4, 6 and $24 \mathrm{~h})$ Data within the same group that are indicated with different lowercase letters are significantly different $(P<0.05)$ between different cotton varieties; data within the same group that are indicated with different uppercase letters are significantly different $(P<0.05)$ among different feeding times. A, lipase; B, trypsin; $\mathrm{C}$, amylase.

\subsubsection{Trypsin}

Cotton variety and feeding time significantly affected the trypsin activity in $S$. exigua $(P<0.001)$. Interactions between cotton variety and feeding time also significantly affected $S$. exigua trypsin activity $(P<0.001)$ (Table 1$)$.

Trypsin activity in $S$. exigua decreased significantly after being fed on Bt cotton $(F=85.52, \mathrm{~d} f=3,12, P=0.0001)$ and non-Bt cotton $(F=12.19, \mathrm{~d} f=3,12, P=0.0006)$ for $24 \mathrm{~h}$, compared with those fed on the same cotton variety for 1,4 and $6 \mathrm{~h}$. Significantly higher trypsin activity $(P<0.001)$ was detected in $S$. exigua fed on Bt cotton for 1, 4, 6 and $24 \mathrm{~h}$, compared with those on non-Bt cotton for the same periods (Figure 2B).

\subsubsection{Amylase}

Cotton variety, feeding time and their interactions had no effect on the $S$. exigua amylase activity $(P>0.05)$ (Table 1$)$.

Amylase activity in $S$. exigua did not differ significantly $(P>0.05)$ after being fed on Bt cotton for different periods. This was also the case for those fed on non-Bt cotton for different time periods. Amylase activities in S. exigua also did not differ significantly $(P>0.05)$ between those fed on $\mathrm{Bt}$ cotton or non-Bt cotton for the same periods (Figure $2 \mathrm{C}$ ).

\subsection{Activities of protection and detoxification enzymes in fourth instar $S$. exigua larvae fed on transgenic Bt cotton vs. non-Bt cotton}

\subsubsection{AChE}

Cotton variety significantly affected the $S$. exigua AChE activity $(P<0.001)$. Interactions between cotton variety and feeding time significantly influenced $S$. exigua AChE activ- 
ity $(P<0.01)$ (Table 1$)$.

AChE activity in $S$. exigua increased significantly after being fed on Bt cotton $(F=7.58, \mathrm{~d} f=3,12, P=0.0042)$ for 24 $\mathrm{h}$, compared with those fed for 1, 4 and $6 \mathrm{~h}$. Significantly lower AChE activities $(P<0.001)$ were detected in $S$. exigua fed on Bt cotton for 1, 4, 6 and $24 \mathrm{~h}$, compared with those fed on non-Bt cotton for the same periods (Figure 3A).

\subsubsection{CarE}

Cotton variety significantly affected $S$. exigua CarE activity $(P<0.001)$. Feeding time also significantly influenced $S$. exigua CarE activity $(P<0.01)$ (Table 1$)$.

CarE activity in $S$. exigua increased significantly after being fed on Bt cotton $(F=6.14, \mathrm{~d} f=3,12, P=0.009)$ or non-Bt cotton $(F=3.74, \mathrm{~d} f=3,12, P=0.0416)$ for $24 \mathrm{~h}$, compared with those fed on the same cotton variety for 1,4 and 6 h. Significantly lower CarE activities $(P<0.001)$ were detected in $S$. exigua fed on Bt cotton for 1, 4, 6 and $24 \mathrm{~h}$, compared with those fed on non-Bt cotton for the same periods (Figure 3B).
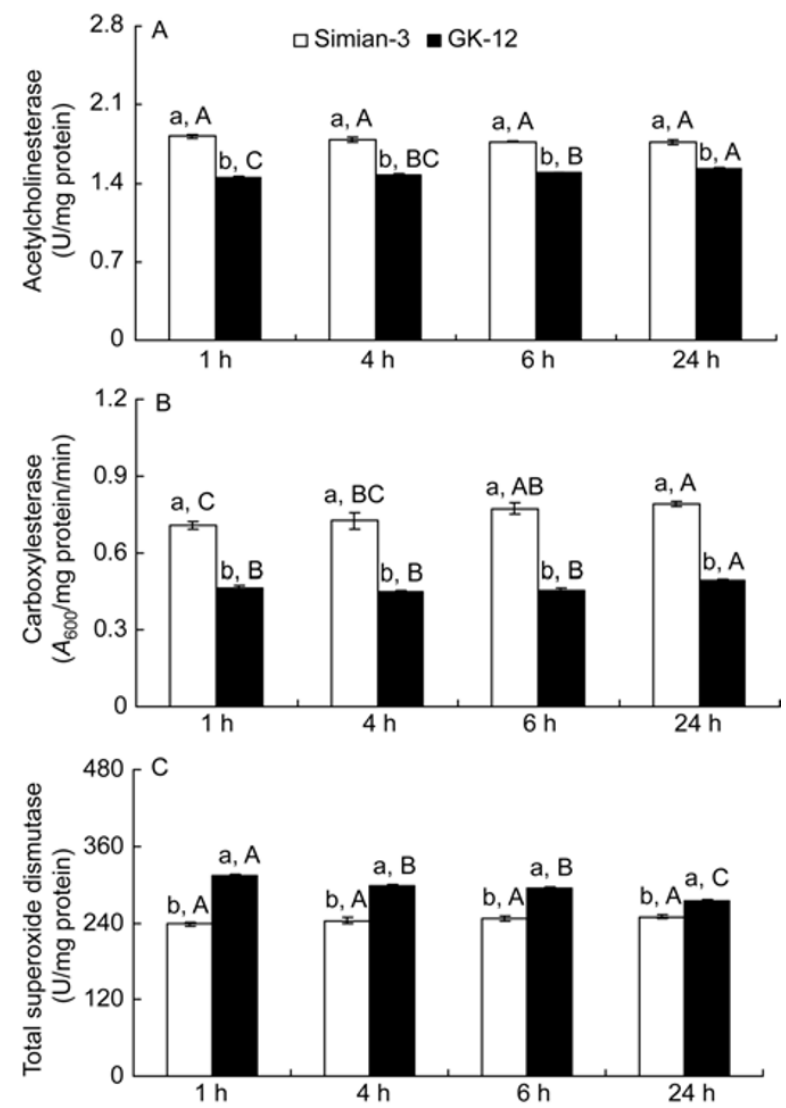

Figure 3 Mean \pm SE activities of protection and detoxification enzymes in fourth instar Spodoptera exigua larvae fed on Bt cotton (cv. GK-12) or non-Bt cotton (cv. Simian-3) for different times (1, 4, 6 and 24 h). Data within the same group indicated with different lowercase letters are significantly different $(P<0.05)$ between different cotton varieties; data within the same group indicated with different uppercase letters are significantly different $(P<0.05)$ among different feeding times. A, acetylcholinesterase; B, carboxylesterase; $\mathrm{C}$, total superoxide dismutase.

\subsubsection{T-SOD}

Cotton variety significantly affected the activities of T-SOD in $S$. exigua $(P<0.001)$. Interactions between cotton variety and feeding time also significantly influenced $S$. exigua T-SOD activity $(P<0.001)$ (Table 1$)$.

T-SOD activity in $S$. exigua decreased significantly after being fed on Bt cotton $(F=33.29, \mathrm{~d} f=3,12, P=0.0001)$ for 24 $\mathrm{h}$, compared with those fed for 1,4 and $6 \mathrm{~h}$. Significantly higher T-SOD activities were detected in $S$. exigua fed on Bt cotton for $1(P<0.001), 4(P<0.001), 6(P<0.001)$ and 24 h $(P<0.001)$, compared with those fed on non-Bt cotton for the same periods (Figure $3 \mathrm{C}$ ).

\section{Discussion}

Annual production of GM crops exceeded $1 \times 10^{8} \mathrm{hm}^{2}$ in 2006. This included Bt cotton expressing insecticidal proteins that occupied $1.34 \times 10^{7} \mathrm{hm}^{2}$, or $13 \%$ of the total [3]. In China, planting of Bt cotton has grown from $6.3 \times 10^{4} \mathrm{hm}^{2}$ in 1998 to $3.5 \times 10^{6} \mathrm{hm}^{2}$ in 2006 , which is equivalent to approximately $60 \%$ of the total cotton area in this country $[3,25]$. Transgenic Bt cotton is considerably effective in controlling lepidopteran pests, and is highly beneficial to growers and the environment by reducing chemical insecticide sprays and preserving populations of beneficial arthropods [26,27]. Currently, there are many publications that have focused on the development and reproduction of herbivorous insects in response to B. thuringiensis. For example, Dutton et al. [28] reported that larval mortality and development of the Egyptian armyworm, Spodoptera littoralis (Boisduval), were negatively affected by Bt maize. Liu et al. [29] reported that larval growth of the cotton bollworm, Helicoverpa armigera (Hübner), was prolonged and its pupation rate and pupal weight decreased when fed on a diet containing Cry1Ac toxin. Liu et al. [30] reported that aphids fed on transgenic $\mathrm{Bt}+\mathrm{CpTI}$ cotton had a shorter reproduction period, longer lifespan, lower survival rate, and earlier occurrence of peak daily mortality in the first or second generation when compared with those fed on non-transgenic cotton.

Insect resistance or tolerance problems is another issue that should be viewed as a part of integrated management strategies including IPM and integrated resistance management (IRM) programs [27]. Since the first commercial release of GM crops expressing Bt genes, there have been environmental impact concerns. In particular, the continuous expression of the insecticidal protein in most tissues of the plant throughout the growing season has raised concerns regarding the development of resistance or tolerance in the target pest, and the possible impacts of this new pest control technology on various groups of non-target organisms of ecological and economic values [20,31,32]. Most herbivores are affected by the physiological and nutritional states of their host plants [33], such as cotton plants expressing 
Cry1Ac toxin. Some pest species have also developed resistance or tolerance to Bt toxin under the continuous selection pressure of the toxic protein [2,34].

Contrasting effects of Bt toxin on herbivorous insects, such as pink bollworm and tobacco budworm, have been reported [35,36]. Chen et al. [37] reported that the population-trend index of cotton bollworm decreased significantly when fed on Bt cotton, compared with the non-Bt cotton fed control. Plutella xylostella fed on a diet containing $\mathrm{Bt}$ laid fewer eggs with lower viability, had reduced larval survival and adult eclosion rates, and ultimately reduced fecundity [38,39]. Carriere et al. [40] reported that resistance to Cry1Ac in Pectinophora gossypiella was associated with over-wintering fitness costs. Other pest species have also been reported to develop $\mathrm{Bt}$ resistance under the continuous selection pressure of the Bt toxin [2,34]. However, not all lepidopteran pest species are equally susceptible to Bt. Some experiments emphasized on the direct negative effects of Bt toxins on non-target herbivores [15,16,41].

Beet armyworm, a non-target herbivorous insect of $\mathrm{Bt}$ cotton, is an important pest in numerous crops and causes economic damage in China. Failure to chemically control this species has shifted the emphasis towards the use of other effective strategies (e.g., transgenic crops) as part of an IPM program. However, widespread concerns about the development of Bt resistance in beet armyworm exist due to previous field resistance to $\mathrm{Bt}$ toxins reported in several lepidopteran families [13]. Most research was conducted using Bt toxins against $S$. exigua [42-44], including the highly effective Cry1C toxin [45,46]. A high level of Cry1C resistance ( $>500$-fold) was found to develop in S. exigua [45].

Transgenic Bt cotton plants are expected to affect certain enzyme activities in lepidopteran herbivores. These include AChE, T-SOD and CarE, which are important protection and detoxification enzymes in herbivorous insect bodies. T-SOD plays an important role in balancing the herbivorous insects' oxidation and anti-oxidation effects, while also protecting the insects' cell from damage caused by harmful environmental factors. AChE directly participates in the functional adjustment of an insect's nervous system. Reduced AChE activity occurs when the insect is exposed to unfavorable environmental stimuli. In our study, the AChE activities in S. exigua decreased significantly by $25.3 \%$, $21.4 \%, 18.6 \%$ and $15.3 \%$ when fed on transgenic Bt cotton for $1,4,6$ and $24 \mathrm{~h}$, respectively, compared with those fed on non-Bt cotton for the same periods. However, the activities of T-SOD increased significantly by $31.5 \%, 22.3 \%$, $18.6 \%$ and $10.2 \%$ after $1,4,6$ and $24 \mathrm{~h}$, respectively. These results indicate that $S$. exigua can develop significant resistance or tolerance to $\mathrm{Bt}$ toxin under continuous selection pressure. We can further speculate that Bt cotton induces changes in the detoxification enzymes of $S$. exigua under the continuous selection pressure of Bt toxin protein. Such enzymatic changes may promote $S$. exigua survival on $\mathrm{Bt}$ cotton and induce the development of larval resistance or tolerance to Bt toxins [6].

Our results indicated that cotton variety significantly affected the activities of the tested digestive enzymes (i.e., lipase and trypsin) except for amylase and the protection and detoxification enzymes (i.e., AChE, CarE and T-SOD) in $S$. exigua. This indicated that $\mathrm{Bt}$ cotton expressing Cry1Ac toxin acted effectively against the tested $S$. exigua enzymes in a similar way to other target pests. Beet armyworm feeding time only significantly affected the activities of trypsin and CarE enzymes in S. exigua. This indicated that the difference between $\mathrm{Bt}$ and non-Bt cotton varieties compared with the beet armyworm feeding time had an overwhelming effect on $S$. exigua enzymatic activity. The interaction between cotton variety and beet armyworm feeding time significantly affected the AChE and T-SOD enzyme activities in $S$. exigua. However, this interaction had no effect on the CarE activity. These results indicated that the activities of different protection and detoxification enzymes in S. exigua were not equally susceptive to Bt cotton after different feeding times.

The development and implementation of effective IRM programs is critical to ensure the long-term durability of $\mathrm{Bt}$ plants [47]. Our study successfully provides a profile to exemplify the direct effects of Bt cotton on nutrient composition and enzyme activities in S. exigua and the responses of this pest species to Bt after different feeding times. Measuring the temporal allocation of protection and detoxification enzyme activities in the body of $S$. exigua in response to Bt can provide a meaningful evaluation of metabolic resistance or tolerance of herbivorous insects under the continuous selection pressure of a toxic protein.

This work was supported by the National Basic Research Program of China (Grant No. 2006CB102004), the National Natural Science Foundation of China (Grant No. 30800724), and New Detecting Technology of Exogenous Gene Protein (Grant Nos. 2008ZX08012-004 and 2009ZX08011013B).

1 Ferry N, Edwards M G, Gatehouse J, et al. Transgenic plants for insect pest control: A forward looking scientific perspective. Transgenic Res, 2006, 15: 13-19

2 Mascarenhas V J, Graves J B, Leonard B R, et al. Susceptibility of field populations of beet armyworm (Lepidoptera: Noctuidae) to commercial and experimental insecticides. J Econ Entomol, 1998, 91: 827-833

3 James C. Global status of commercialized biotech/GM crops: 2006. ISAAA Briefs, No. 35. Ithaca: ISAAA, 2006

4 Zhang S Y, Li D M, Cui J, et al. Effects of Bt-toxin Cry1Ac on Propylaea japonica Thunberg (Col., Coccinellidae) by feeding on Bt-treated Bt-resistant Helicoverpa armigera (Hübner) (Lep., Noctuidae) larvae. J Appl Entomol, 2006, 130: 206-212

5 Blumberg D, Navon A, Goldenberg S K S, et al. Interactions among Helicoverpa armigera (Lepidoptera: Noctuidae), its larval endoparasitoid Microplitis croceipes (Hymenoptera: Braconidae), and Bacillus thuringiensis. J Econ Entomol, 1997, 90: 1181-1186

6 Wu G, Marvin K H, Guo J Y, et al. Response of multiple generations of beet armyworm, Spodoptera exigua (Hübner), feeding on transgenic Bt cotton. J Appl Entomol, 2008, 133: 90-100

7 Schnepf E, Crickmore N, Van Rie J, et al. Revision of the nomencla- 
ture for the Bacillus thuringiensis pesticidal crystal proteins. Microbiol Mol Bio Rev, 1998, 62: 775-806

8 Kranthi K R, Naidu S, Dhawad C S, et al. Temporal and intra-plant variability of Cry1Ac expression in Bt-cotton and its influence on the survival of the cotton bollworm, Helicoverpa armigera. Current Sci, 2005, 89: 291-298

9 Ma X M, Liu X X, Zhang Q W, et al. Assessment of cotton aphids, Aphis gossypii, and their natural enemies on aphid-resistant and aphid-susceptible wheat varieties in a wheat-cotton relay intercropping system. Entomol Exp Appl, 2006, 121: 235-241

10 Shelton A, Zhao J Z, Roush R. Economic, ecological, food safety, and social consequences of the development of Bt transgenic plants. Ann Rev Entomol, 2002, 47: 845-881

11 Chitkowski R L, Turnipseed S G, Sullivan M J, et al. Field and laboratory evaluations of transgenic cottons expressing one and two $\mathrm{Ba}$ cillus thuringiensis var. kurstaki Berliner proteins for management of Noctuid (Lepidoptera) pests. J Econ Entomol, 2003, 96: 755-762

12 Wu K M, Guo Y Y, Lv N, et al. Efficacy of transgenic cotton containing a Cry 1 Ac gene from Bacillus thuringiensis against Helicoverpa armigera (Lepidoptera: Noctuidae) in northern China. J Econ Entomol, 2003, 96: 1322-1328

13 Tabashnik B E. Evolution of resistance to Bacillus thuringiensis. Ann Rev Entomol, 1994, 39: 47-49

14 Dingha B N, Moar W, Apple A G. Effects of Bacillus thuringiensis Cry $1 \mathrm{C}$ toxin on the metabolic rate of Cry $1 \mathrm{C}$ resistant and susceptible Spodoptera exigua (Lepidoptera: Noctuidae). Physiol Entomol, 2004, 29: 409-418

15 Adamczyk J J Jr., Holloway J W, Church G E, et al. Larval survival and development of the fall armyworm (Lepidoptera: Noctuidae) on normal and transgenic cotton expressing the Bacillus thuringiensis Cry1A(c)-endotoxin. J Econ Entomol, 1998, 91: 539-545

16 Stewart S D, Adamczyk J J, Knighten K S, et al. Impact of Bt cotton expressing one or two insecticidal proteins of Bacillus thuringiensis Berliner on growth and survival of noctuid (Lepidoptera) larvae. J Econ Entomol, 2001, 94: 752-760

17 Shi H, Zhang L F, Hua B Z, et al. Insecticidal activity of residual Bt protein at the second trophic level. Chin Sci Bull, 2006, 51: 946-951

18 Guo T B, Ji B Z, Zhu G Q, et al. Effect of transgenic poplars on the activities of detoxification enzymes in Micromelalopha troglodyta larvae. Scientia Silvae Sinicae, 2007, 43: 59-63

19 Gutierrez A P, Adamczyk J J, Ponsard S, et al. Physiologically based demographics of $\mathrm{Bt}$ cotton-pest interactions II. Temporal refuges, natural enemy interactions. Ecol Model, 2006, 191: 360-382

20 Dong H Z, Li W J. Variability of endotoxin expression in Bt transgenic cotton. J Agron Crop Sci, 2007, 193: 21-29

21 Li G H, Chen Q J, Pang Y. Studies of artificial diets for the beet armyworm, Spodoptera exigua. Acta Sci Nat Univ Sunyatseni, 1998, 37: $1-5$

22 Van Asperen K. A study of house fly esterase by means of a sensitive colourimetric method. J Insect Physiol, 1962, 8: 401-416

23 Bradford M M. A rapid and sensitive method for the quantification of microgram quantities of protein utilizing the principle of protein binding. Anal Biochem, 1976, 72: 248-254

24 SAS Institute Inc. SAS/STAT software: Changes and enhancements through release 6.12. Cary (NC): SAS Institute Inc. 1996

25 James C. Global review of commercialized transgenic crops: 1998. ISAAA Briefs, No. 8. Ithaca: ISAAA, 1998

26 Pray C, Ma D M, Huang J K, et al. Impact of Bt cotton in China. World Develop, 2001, 29: 813-825

27 Wu K M, Guo Y Y. The evolution of cotton pest management practices in China. Ann Rev Entomol, 2005, 50: 31-52

28 Dutton A, Romeis J, Bigler F. Effects of Bt maize expressing Cry1 Ab and Bt spray on Spodoptera littoralis. Entomol Exp Appl, 2005, 114:
$161-169$

29 Liu X X, Zhang Q W, Zhao J Z, et al. Effects of the Cry1Ac toxin of Bacillus thuringiensis on Microplitis mediator, a parasitoid of the cotton bollworm, Helicoverpa armigera. Entomol Exp Appl, 2005a, 114: $205-213$

30 Liu X D, Zhai B P, Zhang X X, et al. Impact of transgenic cotton plants on a non-target pest, Aphis gossypii Glover. Ecol Entomol, 2005b, 30: 307-315

31 Dutton A, Klein H, Romeis J, et al. Uptake of Bt-toxin by herbivores feeding on transgenic maize and consequences for the predator Chrysoperla carnea. Ecol Entomol, 2002, 27: 441-447

$32 \mathrm{Wu}$ K M, Guo Y Y, Lv N, et al. Resistance monitoring of Helicoverpa armigera (Lepidoptera: Noctuidae) to Bacillus thuringiensis insecticidal protein in China. J Econ Entomol, 2002, 95: 826-831

33 Coviella C E, Trumble J T. Effects of elevated atmospheric carbon dioxide on insect-plant interactions. Conserv Biol, 1999, 13: 700-712

34 Tabashnik B E, Liu Y B, Dennehy T J, et al. Inheritance of resistance to Bt toxin Cry1Ac in a field-derived strain of pink bollworm (Lepidoptera: Gelechiidae). J Econ Entomol, 2002, 95: 1018-1026

35 Wilson W D, Flint H M, Deaton R W, et al. Resistance of cotton lines containing a Bacillus thuringiensis toxin to pink bollworm (Lepidoptera: Gelechiidae) and other insects. J Entomol Sci, 1992, 34: 415-425

36 Cui J J, Xia J Y. Effects of Bt (Bacillus thuringiensis) transgenic cotton on the dynamics of pest population and their enemies. Acta Phytophyl Sin, 2000, 27: 141-145

37 Chen F J, Wu G, Parajulee M N, et al. Long-term impacts of elevated carbon dioxide and transgenic Bt cotton on performance and feeding of three generations of cotton bollworm. Entomol Exp Appl, 2007, 124: $27-35$

38 Groeters F R, Tabashnik B E, Finson N, et al. Resistance to Bacillus thuringiensis affects mating success of diamondback moth (Lepidoptera: Plutellidae). J Econ Entomol, 1993, 86: 1035-1039

39 Groeters F R, Tabashnik B E, Finson N J, et al. Fitness costs of resistance to Bacillus thuringiensis in the diamondback moth (Plutella xylostella). Evolution, 1994, 48: 197-201

40 Carriere Y, Ellers-Kirk C, Patin A L, et al. Over wintering cost associated with resistance to transgenic cotton in the pink bollworm (Lepidoptera: Gelechiidae). J Econ Entomol, 2001, 94: 935-941

41 Zhang Y J, Wu K M, Guo Y Y. On the spatio-temporal expressing of the contents of Bt insecticidal protein and the resistance of Bt transgenic cotton to cotton bollworm. Acta Phytophysiol Sin, 2001, 28: 1-6

42 Luo K, Adang M J. Removal of adsorbed toxin fragments that modify Bacillus thuringiensis Cry1C delta-endotoxin iodination and binding by sodium dodecyl sulfate treatment and renaturation. Appl Environ Microbiol, 1994, 60: 2905-2910

43 Stapel J O, Waters D J, Ruberson J R, et al. Development and behavior of Spodoptera exigua (Lepidoptera: Noctuidae) larvae in choice tests with food substrates containing toxins of Bacillus thuringiensis. Biol Control, 1998, 11: 29-37

44 Ashfaq A, Young S Y, McNew R W. Development of Spodoptera exigua and Helicoverpa zea (Lepidoptera: Noctuidae) on transgenic cotton containing Cry1Ac insecticidal protein. J Entomol Sci, 2000, 35: $360-372$

45 Moar W J, Pusztai-Carey M, Van Faassen H, et al. Development of Bacillus thuringiensis Cry1C resistance by Spodoptera exigua (Hübner) (Lepidoptera: Noctuidae). Appl Environ Microbiol, 1995, 61: 2086-2092

46 Berdegue M, Trumble J T, Moar W J. Effect of Cry1C toxin from Bacillus thuringiensis on larval feeding behavior of Spodoptera exigua. Entomol Exp Appl, 1996, 80: 389-401

47 Huang F N. Detection and monitoring of insect resistance to transgenic Bt crops. Insect Sci, 2006, 13: 73-84

Open Access This article is distributed under the terms of the Creative Commons Attribution License which permits any use, distribution, and reproduction in any medium, provided the original author(s) and source are credited. 